\title{
Lithium Augmentation Increases the ACTH and Cortisol Response in the Combined DEX/ CRH Test in Unipolar Major Depression
}

Tom Bschor, M.D., Mazda Adli, M.D., Christopher Baethge, M.D., Uta Eichmann, Marcus Ising, Ph.D., Manfred Uhr, M.D., Sieglinde Modell, M.D., Heike Künzel, M.D., Bruno Müller-Oerlinghausen, M.D., and Michael Bauer, Ph.D., M.D.

Lithium augmentation is a well established strategy for treatment-resistant depression. The exact mode of its action is unknown, but an enhancement of serotonergic transmission is hypothesized. The authors investigated changes in the hypothalamic-pituitary-adrenocortical (HPA) system during lithium augmentation and their correlation to clinical response by means of the combined dexamethasone/CRH test (DEX/CRH test). Thirty patients with unipolar major depressive episodes (DSM IV) who had not responded to an adequate trial with an antidepressant were assessed on the day before lithium augmentation (baseline) with the DEX/CRH test (pretreatment with 1.5 mg dexamethasone p.o. at 11 P.M. and CRH stimulation at 3 P.M. on the next day). Twenty-four patients were reassessed after response was determined or, in cases of nonresponse, four weeks after initiation of lithium augmentation. Response to lithium augmentation was measured by weekly ratings on the Hamilton Depression
Rating Scale (HDRS 17-item version). Response was defined as a $\triangle H D R S$ of $\geqslant 50 \%$ and an endpoint score of $<10$. Patients had a significantly higher ACTH and cortisol response to CRH stimulation during lithium augmentation compared with the values at baseline. There was no difference in $A C T H$ and cortisol reaction between responders and non-responders to lithium augmentation. This increase is in contrast to the known normalization of HPA-axis overdrive after treatment with a tricyclic antidepressant like amitriptyline. Because the effect was independent of response status we suggest that this increase reflects an effect of lithium that is independent from the psychopathological state or its change. This effect might be explained by the serotonergic effects of lithium.

[Neuropsychopharmacology 27:470-478, 2002] (C) 2002 American College of Neuropsychopharmacology. Published by Elsevier Science Inc.
KEY WORDS: Lithium augmentation; Major depression; Cortisol; ACTH; HPA System; DEX/CRH Test; Neuroendocrinology

From the Department of Psychiatry, Technische Universität Dresden, Dresden, Germany (TB), Department of Psychiatry, Freie Universität Berlin, Berlin, Germany (MA, CB, UE, BM-O), Max-Planck Institute of Psychiatry, Munich, Germany (MI, MU, SM, HK), Neuropsychiatric Institute \& Hospital, Department of Psychiatry and Biobehavioral Sciences, University of California at Los Angeles (UCLA), Los Angeles, California, USA (MB).

Presented in part at the $7^{\text {th }}$ World Congress of Biological Psychiatry, Berlin, Germany, July 1-6, 2001 and at the International Con-
Regardless of the initial choice of antidepressant, about 30 to $40 \%$ of patients with major depressive disorder will not respond sufficiently (Thase and Rush 1995).

gress of the World Psychiatric Association, Madrid, Spain, September 30 - October 4, 2001.

Address correspondence to: Dr. Tom Bschor, Department of Psychiatry, Technische Universität Dresden, Fetscherstrasse, 74 D01307, Dresden, Germany. Tel.: +49-351-458 3595; Fax: +49-351-458 5316; E-mail: bschor@mailbox.tu-dresden.de

Received November 26, 2001; revised February 19, 2002; accepted February 26, 2002.

Online publication: $3 / 4 / 02$ at www.acnp.org/citations/ Npp030402258. 
Among the various treatment options that have been proposed for non-responding depressed patients, lithium augmentation has been recommended as a first-line strategy (Bauer et al. 2002). The efficacy of lithium augmentation has been well documented in placebo-controlled acute (Joffe et al. 1993; Katona et al. 1995; Baumann et al. 1996) and continuation treatment trials (Bauer et al. 2000; Bschor et al. 2002) using different classes of antidepressants. A recent meta-analysis confirmed the evidence that lithium augmentation is superior to placebo augmentation for the treatment of unipolar major depression, with a median response rate of $50 \%$ across double-blind studies (Bauer and Döpfmer 1999).

Severity of depression was recently identified as a clinical predictor of response to lithium augmentation (Bschor et al. 2001). Better knowledge of the neurobiological mechanisms of lithium augmentation would help to identify patients who will respond favorably to this treatment intervention. However, to date, the mode of action of lithium augmentation is unknown. Shortly after the initial report on its efficacy (de Montigny et al. 1981), it was postulated by de Montigny et al. (1983) that a pharmacodynamic action mediated via the serotonergic systems might account for the synergistic effect of lithium when added to a tricyclic antidepressant.

Another system potentially involved in its mechanism of action is the hypothalamic-pituitary-adrenocortical (HPA) system, putatively the best studied biological system in affective disorders (Dinan 1997). The most sensitive challenge test of the HPA system is the combined dexamethasone/CRH test (DEX/CRH test) (Heuser 1998). A dysfunction in the regulation of the HPA system, especially an overstimulation of ACTH and cortisol in the DEX/CRH test, was repeatedly shown in depressed patients (for a review see Steckler et al. 1999; Holsboer 2000). In treatment studies with amitriptyline, a normalization of the HPA system dysregulation, (i. e., normalization of the overstimulation of ACTH and cortisol secretion), was found to precede the clinical improvement (Heuser et al. 1996). Subsequently, it has been hypothesized that antidepressant treatment might develop its action through direct effects on the HPA system, particularly by enhancing cellular corticosteroid receptors, leading to a normalization of defective glucocorticoid feedback inhibition (Barden et al. 1995).

With regard to lithium augmentation, there are few studies and the results are contradictory. The dexamethasone suppression test has been conducted (but not the combined DEX/CRH test) before onset of lithium augmentation to examine its predictive value for the outcome of the augmenting strategy (for a review see de Montigny 1994). However, none of the latter studies investigated changes in the HPA system induced by lithium augmentation. Lithium induces multiple intracellular modifications (Wood and Goodwin 1987; Watson and Young 2001) and it can be hypothesized that it also impacts the HPA system, which might have some importance for its clinical effects.
The goal of the present study was to investigate the HPA system in unipolar major depression before and during lithium augmentation by means of the combined DEX/CRH test.

\section{METHOD}

This study was conducted at the Department of Psychiatry, Freie Universität Berlin, a tertiary care academic medical center, and included only inpatients from the clinical programs. The study protocol was approved by the local ethical committee. After complete description of the study to the subjects, written informed consent was obtained. The laboratory analyses of ACTH and cortisol and the statistical analyses were performed at the Max-Planck Institute of Psychiatry, Munich.

Patients of both genders, age 18 years or older, with a major depressive episode, single episode or recurrent (DSM IV criteria), were included in the study. Diagnoses were confirmed by the Structured Clinical Interview for DSM IV (SCID I; German version) (Wittchen et al. 1997). Participants had to be non-responders to an antidepressant monotherapy trial of at least four weeks with an appropriate dosage (150 mg/d imipramine equivalent). On the day of study, included participants had to have met criteria for a major depressive episode with a score of at least 15 on the Hamilton Depression Rating Scale, 17-item version $\left(\mathrm{HDRS}_{17}\right)$ (Hamilton 1960). The exclusion criteria were: a history of a manic or hypomanic episode; any other DSM-IV Axis I diagnosis; severe somatic conditions and conditions that influence the regulation of mineralo- or glucocorticoids; medical conditions incompatible with lithium therapy; pregnancy or lactation; organic brain diseases.

Thirty of 35 patients who met the inclusion criteria were subsequently enrolled into the study (five patients refused participation in the study for various reasons). Patients were treated with lithium as an additive (augmentation) to standard antidepressants. Patients received antidepressants from different classes: seven were treated with tricyclic antidepressants (mean daily dose \pm SD: $246.4 \pm 58.5 \mathrm{mg})$, nine with paroxetine $(63.3 \pm$ $18.7 \mathrm{mg} / \mathrm{d})$, five with venlafaxine $(285.0 \pm 62.7 \mathrm{mg} / \mathrm{d})$. Stable medical comedication was allowed; eight patients received a stable neuroleptic comedication and one patient was treated with benzodiazepines $(10 \mathrm{mg}$ diazepam/d). The $\mathrm{HDRS}_{17}$ score was $20.0 \pm 3.81$ (mean \pm SD) (range: 15-30) at study entry. For details on the antidepressant medication and for demographic data see Table 1.

\section{Study Design}

As shown in Figure 1, patients started lithium augmentation treatment on the evening of the first combined DEX/CRH test (baseline). Lithium was administered at 
Table 1. Demographic and Clinical Variables (Mean, SD) in 30 Patients with Major Depressive Disorder who Responded or did not Respond to a 4-Week Lithium Augmentation Trial

\begin{tabular}{|c|c|c|c|c|c|}
\hline & \multicolumn{2}{|c|}{$\begin{array}{l}\text { Responder } \\
(\mathbf{n}=11)\end{array}$} & \multicolumn{2}{|c|}{$\begin{array}{l}\text { Non-responder } \\
\quad(n=19)\end{array}$} & \multirow[t]{2}{*}{$\begin{array}{c}\text { Mann-Whitney } \\
\text { U test } \\
\text { (2-tailed } p \text { ) }\end{array}$} \\
\hline & Mean & SD & Mean & SD & \\
\hline Age (years) & 50.82 & 16.03 & 43.74 & 16.39 & 0.401 \\
\hline Age at onset of mood disorder (years) & 39.22 & 15.96 & 38.06 & 17.18 & 0.959 \\
\hline \multicolumn{6}{|l|}{ HDRS score at initiation of } \\
\hline lithium augmentation & 20.91 & 4.53 & 19.47 & 3.34 & 0.502 \\
\hline Duration of index episode (weeks) & 27.14 & 13.09 & 51.37 & 53.97 & 0.343 \\
\hline Number of previous depressive episodes & 2.36 & 2.50 & 2.37 & 2.99 & 0.866 \\
\hline \multirow[t]{2}{*}{ Number of previous psychiatric hospitalizations } & 1.73 & 1.68 & 1.32 & 1.29 & 0.582 \\
\hline & & & $\begin{array}{c}\text { Responder } \\
(\mathrm{n}=11)\end{array}$ & $\begin{array}{l}\text { Non-responder } \\
(\mathbf{n}=19)\end{array}$ & $\begin{array}{c}\text { Fisher exact test } \\
\quad(2 \text {-tailed } p)\end{array}$ \\
\hline Gender (male:female) & & & $4: 7$ & 9:10 & 0.708 \\
\hline \multicolumn{6}{|l|}{ Antidepressive Medication } \\
\hline & $\begin{array}{l}\text { mean dosage } \\
(\mathrm{mg} / \mathrm{d})\end{array}$ & SD & & & \\
\hline Amitriptyline & 275 & 43.3 & 1 & 2 & 1.000 \\
\hline Citalopram & 55 & 7.1 & 1 & 1 & 1.000 \\
\hline Clomipramine & 150 & & 1 & 0 & 0.367 \\
\hline Doxepine & 250 & 50.0 & 0 & 3 & 0.279 \\
\hline Mirtazapine & 50 & 8.7 & 0 & 3 & 0.279 \\
\hline Paroxetine & 63.3 & 18.7 & 4 & 5 & 0.687 \\
\hline Reboxetine & 11 & 1.4 & 1 & 1 & 1.000 \\
\hline Sertraline & 150 & 0 & 0 & 2 & 0.520 \\
\hline Venlafaxine & 285 & 62.7 & 3 & 2 & 0.327 \\
\hline
\end{tabular}

a daily dose of two times $12.2 \mathrm{mmol}$ lithium carbonate $(2 \times 450 \mathrm{mg})$ while the antidepressant was continued at the previous dosage. Standardized 12-hour serum lithium levels were measured at day 4 and at the end of each week (on day $7,14,21,28$ ) of lithium augmentation. The lithium dose was adapted individually to achieve a serum level between 0.5 and $1.0 \mathrm{mmol} / \mathrm{L}$. Lithium serum levels $(\mathrm{mmol} / \mathrm{L})$ and lithium doses (mmol/d) were as follows (mean $\pm \mathrm{SD})$ : at day 7 of lithium augmentation: $0.54 \pm 0.14 / 22.8 \pm 5.5$; at day 14: $0.71 \pm 0.15 / 26.8 \pm 6.7$; at day 21: $0.68 \pm 0.13 / 26.5 \pm$ 7.1; and at day 28: $0.71 \pm 0.18 / 24.7 \pm 10.1$.

The $\mathrm{HDRS}_{17}$ was conducted at weekly intervals (on day $7,14,21,28$ ) between 12 A.M. and 3 P.M. All ratings were performed by the same rater (U. E.). Patients were classified as responders to lithium augmentation if their HDRS $_{17}$-score (I) showed a decrease of $50 \%$ or more and (II) a total of $<10$. Response had to be confirmed after one week by both criteria. If patients did not fulfill these response criteria within a maximum of four weeks after start of lithium augmentation, they were classified as non-responders to lithium augmentation.

The patients were re-examined with the combined DEX/CRH test depending on the time of response to lithium augmentation: Non-responders were re-examined after four weeks, whereas responders were reassessed immediately after response was determined in order to investigate the HPA system of the responders as soon as possible after the change in psychopathology. Because response criteria had to be confirmed one week after they were first met, the re-assessment of responders was done after two weeks at the earliest. Six patients (five non-responder and one responder) refused re-assessment with the combined DEX/CRH test; consequently test data from 24 patients were available.

\section{The Dexamethasone/CRH Test}

The combined DEX/CRH test was performed as described in detail elsewhere (Heuser et al. 1994, 1996). The patients were pretreated with an oral dose of 1.5 $\mathrm{mg}$ of dexamethasone at 11 P.M. The next day, blood was drawn at 3 P.M., 3:30 P.M., 3:45 P.M., 4 P.M., 4:15 P.M., and 4:30 P.M. through an intravenous catheter (through the wall technique). $100 \mu \mathrm{g}$ of human CRH was administered intravenously at 3 P.M. shortly after the first blood collection. All blood samples were collected in pre-frozen, EDTA- and aprotinin(Trasylol ${ }^{\mathrm{TM}}$ )-containing tubes and immediately centrifuged in a cooled centrifuge at $4^{\circ} \mathrm{C}$. Plasma was frozen directly after separation from the blood cells and stored at $-80^{\circ} \mathrm{C}$.

The plasma cortisol and ACTH concentrations in the first specimen, collected at 3 P.M., reflect the suppressive effects of the dexamethasone administered the day before, whereas the other five plasma cortisol and ACTH concentrations reflect the additional effects of the $\mathrm{CRH}$ 


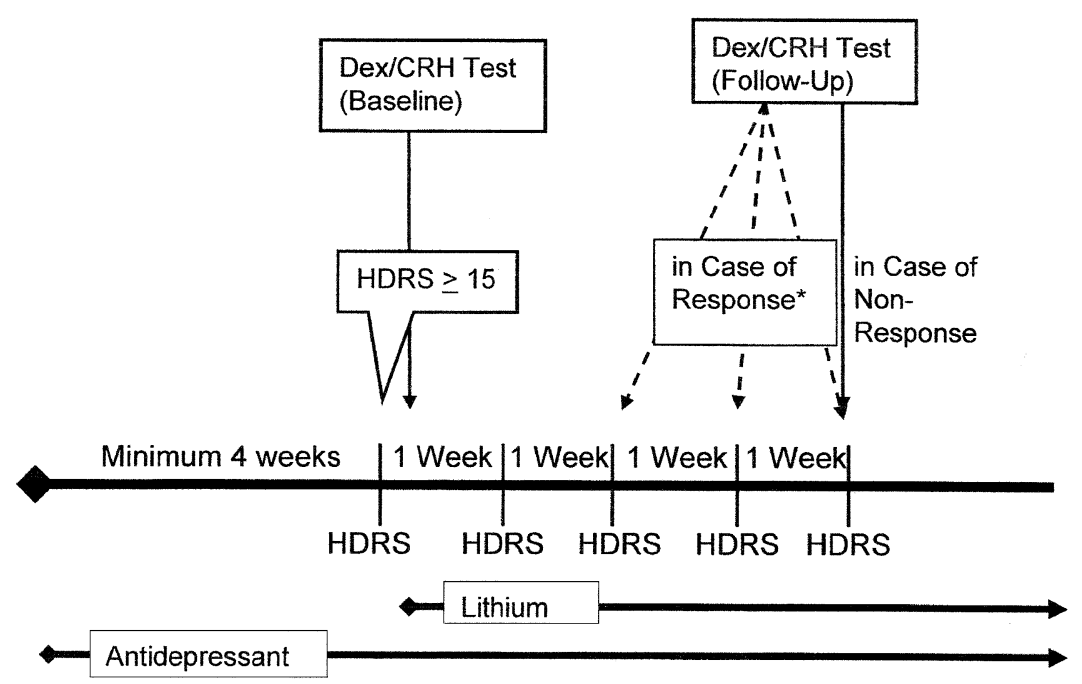

Figure 1. Design and procedures of a study on the effects of lithium augmentation on the combined dexamethasone/CRH test in unipolar major depression. ${ }^{*}$ The timepoint of the re-test depended on the response status: Responders were re-assessed immediately after response was determined; nonresponders were re-assessed after four weeks. Response criterion: At two consecutive assessments (during an 1-week interval) reduction of the HDRS score by $\geqslant 50 \%$ and an endscore of $<10$. Abbreviations: Dex $=$ dexamethasone, HDRS = Hamilton Depression Rating Scale (17-item version) stimulation. Peak levels, CRH response values (delta) and area under the curve (AUC) values of cortisol and $\mathrm{ACTH}$ in the six consecutive blood samples were used as indicators of the response to the combined DEX/ $\mathrm{CRH}$ test. The delta values were obtained by subtracting the 3 P.M. hormone values (before $\mathrm{CRH}$ injection) from the individual peak value. The AUC values were defined as the natural logarithms of the trapezoidal integration of the six cortisol and ACTH concentrations.

All probes were analyzed together in one assay at the end of the entire study. For the determination of the plasma cortisol concentration a commercially available radioimmunoassay (RIA) kit (ICN Biomedicals, Carson, CA) was used. The detection limit was $0.3 \mathrm{ng} / \mathrm{ml}$ plasma; intra- and interassay coefficients of variation for 20 and $40 \mathrm{ng} / \mathrm{ml}$ were $<7 \%$. For plasma ACTH measurements an immunoradiometric assay without extraction (Nichols Institute, San Juan Capistrano, CA) was used providing a detection limit of $4.0 \mathrm{pg} / \mathrm{ml}$. The intra- and interassay coefficients of variation at $20 \mathrm{pg} /$ $\mathrm{ml}$ plasma were $<8 \%$.

\section{Statistical Analysis}

Changes between the initial endocrine variables at baseline and at follow-up were evaluated with Wilcoxon's matched pairs test. Differences between responders and non-responders to lithium augmentation were assessed with Fisher's exact test and Mann-Whitney $U$ test. Differences were regarded as significant when $p<.05$.

\section{RESULTS}

Eleven (37\%) of the 30 patients (four men, seven women) fully responded within four weeks after initiation of lith- ium augmentation treatment (in mean after $2.9 \pm 0.8$ weeks; final mean $\mathrm{HDRS}_{17}: 4.9 \pm 1.9$ ). Nineteen patients (9 men, 10 women) continued to be depressed at the end of the lithium augmentation trial (final HDRS 17 : $17.1 \pm$ 4.9). There was no significant gender difference between responders and non-responders to lithium augmentation (Fisher's exact test, 2-tailed $p=.708$ ). Furthermore, there were no significant differences between responders and non-responders in age, age at onset of the mood disorder, duration of index episode, number of previous depressive episodes, number of previous psychiatric hospitalizations, baseline HDRS, or in the type of antidepressive medication (Mann-Whitney U tests, Fisher's exact tests, cf. Table 1).

At baseline, the ACTH peak was $18.85 \pm 10.9 \mathrm{pg} / \mathrm{ml}$ and the cortisol peak was $55.28 \pm 44.8 \mathrm{ng} / \mathrm{ml}$ (for AUC and delta values cf. Table 2). There was no difference for any parameter between responders and non-responders (Mann-Whitney U test, cf. Table 2).

Both the ACTH and the cortisol response significantly increased in the combined DEX/CRH test during lithium augmentation treatment (ACTH peak: $34.48 \pm$ $30.5 \mathrm{pg} / \mathrm{ml}$, cortisol peak: $82.98 \pm 60.6 \mathrm{ng} / \mathrm{ml}$; both $p=$ .004. AUC and delta values for both ACTH and cortisol also increased significantly during lithium augmentation.) (Table 3 and Figure 2). The ACTH and the cortisol response increased both in responders as well as in non-responders, but failed to reach the significance level for the ACTH parameters and for the cortisol delta value in the non-responder group (Table 3 ).

\section{DISCUSSION}

To our knowledge, this is the first study that has examined the effects of lithium augmentation on the HPAsystem by means of the combined DEX/CRH test in pa- 
Table 2. ACTH (pg/ml) / Cortisol (ng/ml) Responses to the Combined DEX/CRH Test at Baseline in Patients who Responded or did not Respond to Lithium Augmentation (Mean, SD).

\begin{tabular}{|c|c|c|c|c|c|}
\hline & \multicolumn{2}{|c|}{$\begin{array}{l}\text { Responder } \\
(\mathbf{n}=11)\end{array}$} & \multicolumn{2}{|c|}{$\begin{array}{l}\text { Non-responder } \\
\quad(n=19)\end{array}$} & \multirow{2}{*}{$\begin{array}{c}\text { Mann-Whitney U test } \\
\text { (2-tailed p) }\end{array}$} \\
\hline & Mean & SD & Mean & SD & \\
\hline ACTH Peak value & 21.32 & 14.41 & 17.62 & 7.31 & 0.576 \\
\hline ACTH AUC* & 7.11 & 0.51 & 6.93 & 0.39 & 0.322 \\
\hline ACTH Delta & 14.89 & 13.11 & 10.89 & 7.43 & 0.451 \\
\hline Cortisol Peak value & 53.32 & 54.27 & 60.47 & 34.03 & 0.312 \\
\hline Cortisol AUC* & 7.62 & 0.89 & 7.98 & 0.65 & 0.237 \\
\hline Cortisol Delta & 41.58 & 52.43 & 46.54 & 33.31 & 0.312 \\
\hline
\end{tabular}

*AUC values are log-transformed (natural logarithms)

tients with unipolar major depression. Eleven (37\%) of 30 depressed patients, refractory to an adequate antidepressant treatment trial, responded to this 4-week treatment intervention. This is somewhat less than the median response rate $(50 \%)$ seen in placebo-controlled lithium augmentation trials, but still within the range of what was reported by other groups (range $12.5 \%$ to $62.5 \%$ ) (Bauer and Döpfmer 1999).

This study revealed three main results: Patients showed an increase in the ACTH and cortisol response in the combined DEX/CRH test under lithium augmentation as compared with baseline. This increase was found both in responders and in non-responders to lithium augmentation. The baseline examination did not show an exaggerated ACTH and cortisol response in the DEX/CRH test as could be expected from previous studies with depressed patients.

The significant increase of the ACTH and cortisol response under lithium augmentation was an unexpected result of the present study. An increase in the DEX/ $\mathrm{CRH}$ response under treatment (especially in responders) is not in line with the concept of an elevated response in the combined DEX/CRH test as a pathological state marker of acute depression and its normalization after successful treatment (Steckler et al. 1999; Holsboer 2000). According to this concept, an antidepressantinduced normalization of the overstimulation is critical for relief of the clinical symptoms of depression. Accordingly, an elevation of the ACTH and cortisol response in the combined DEX/CRH test as assessed in this study should be associated with a worsening of the depressive condition.

The baseline results of the combined DEX/CRH test did not show HPA system overstimulation, as was found by other authors in unmedicated depressed patients. Although comparisons with previous studies have some obvious methodological limitations, it is of interest that others found a peak ACTH of $19.55 \mathrm{pg} / \mathrm{ml}$ (equivalent to $4.3 \mathrm{pmol} / \mathrm{l}$ ) in healthy controls as compared with $29.55 \mathrm{pg} / \mathrm{ml}(6.5 \mathrm{pmol} / \mathrm{l})$ in medication free depressed patients (Holsboer et al. 1995). Our group of depressed patients had a peak ACTH of only $18.85 \mathrm{pg} /$ $\mathrm{ml}$ before lithium augmentation although they were 12 years older on average. Age was found to be associated with a more prominent dysregulation of the HPA system (von Bardeleben and Holsboer 1991). Interestingly,

Table 3. Changes Between ACTH (pg/ml) and Cortisol (ng/ml) Values at Baseline and at Follow-Up (after Response to Lithium Augmentation or after 4 Weeks in Case of Non-response) in Patients who Responded or did not Respond to Lithium Augmentation and in the Total Group of Patients (Mean, SD).

\begin{tabular}{|c|c|c|c|c|c|c|c|c|c|c|c|c|c|c|c|}
\hline \multirow[b]{3}{*}{ DEX/CRH Test } & \multicolumn{5}{|c|}{ Responder $(n=10)$} & \multicolumn{5}{|c|}{ Non-responder $(n=14)$} & \multicolumn{5}{|c|}{ Total $(\mathrm{n}=24)$} \\
\hline & \multicolumn{2}{|c|}{ Baseline } & \multicolumn{2}{|c|}{ Follow-up } & \multirow[b]{2}{*}{$p^{1}$} & \multicolumn{2}{|c|}{ Baseline } & \multicolumn{2}{|c|}{ Follow-up } & \multirow[b]{2}{*}{$p^{1}$} & \multicolumn{2}{|c|}{ Baseline } & \multicolumn{2}{|c|}{ Follow-up } & \multirow[b]{2}{*}{$p^{1}$} \\
\hline & Mean & SD & Mean & SD & & Mean & SD & Mean & SD & & Mean & SD & Mean & SD & \\
\hline $\mathrm{ACTH}$ & 22.33 & 14.8 & 38.71 & 32 & 0 & 16.36 & 6.4 & 31.46 & 25 & 0.064 & 18.85 & 10.9 & 34.48 & 30.5 & 0.004 \\
\hline ACTH AUC* & 7.12 & 0.52 & 7.34 & 0.73 & 0.086 & 6.86 & 0.40 & 7.18 & 0.77 & 0.075 & 6.97 & 0.46 & 7.25 & 0.74 & 0.017 \\
\hline ACTH Delta & 15.66 & 13.6 & 30.01 & 28.3 & 0.028 & 9.92 & 5.52 & 18.49 & 20.9 & 0.279 & 12.41 & 10.0 & 23.50 & 24.5 & 0.012 \\
\hline Cortisol Peak value & 56.70 & 56.0 & 87 & 66 & 0.047 & 54.26 & 37.1 & 79 & 58.3 & & 55.28 & 44.8 & 82.98 & 6 & 0.004 \\
\hline Cort & & 0.93 & & 0. & & & 0 . & & 0 . & & 7.77 & 0.79 & & & 0.001 \\
\hline Cortisol Delta & 44.24 & 54.5 & 70.76 & 59.6 & 0.047 & 39.76 & 35.8 & 56.93 & 51.1 & 0.074 & 41.63 & 43.5 & 62.69 & 54.0 & 0.009 \\
\hline
\end{tabular}

${ }^{1}$ Wilcoxon's matched pairs test

*AUC values are log-transformed (natural logarithms) 

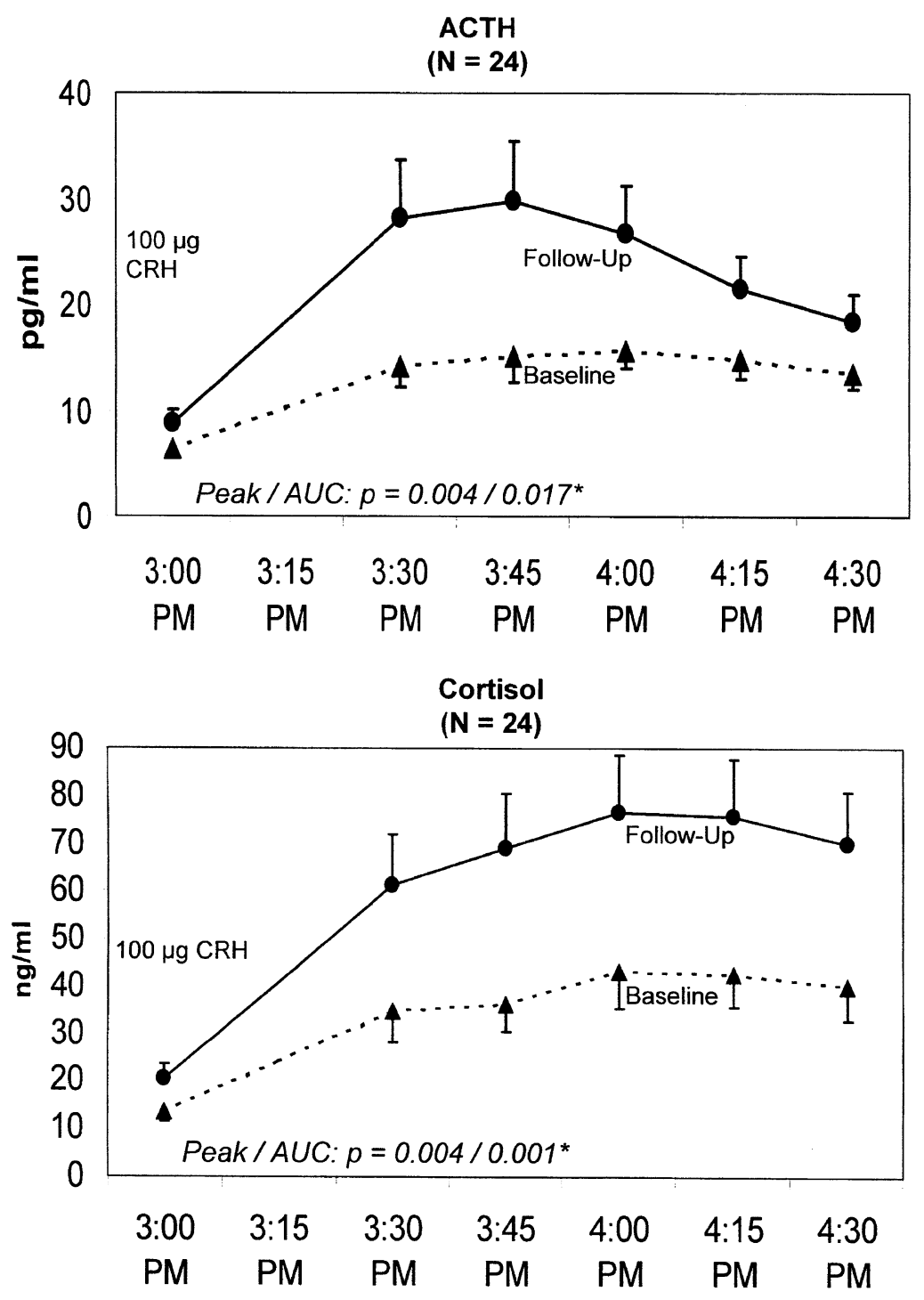

Figure 2. ACTH and cortisol response in the combined DEX/CRH test on the day before lithium augmentation (baseline) and during lithium augmentation (follow-up) $(n=24)$.

*Wilcoxon's matched pairs test

lithium augmentation led to DEX/CRH test results (e.g., ACTH peak $=34.48 \mathrm{pg} / \mathrm{ml}$ ) that were comparable to those found in previous studies investigating medication-free depressed subjects (Holsboer et al. 1995).

Prior to entry into our study, depressed patients had a HDRS $_{17}$ score of at least 15 , but it should be noted that at baseline, all patients were administered antidepressive medication (though ineffective) at adequate doses for at least four weeks. This might explain the apparently normal HPA system regulation as investigated with the combined DEX/CRH test. Heuser et al. (1996) showed a significant decrease of the ACTH and cortisol response in the DEX/CRH test under amitriptyline treatment independent of response. In our study, the apparently unelevated ACTH and cortisol response at baseline assessment would be in line with the latter finding. It can be hypothesized that lithium augmentation and tricyclic antidepressants may influence the
HPA system regulation at different targets, possibly both leading to clinical improvement but to a different response to the combined DEX/CRH challenge.

The explanation of the underlying neurobiological mechanism through which lithium augmentation leads to the elevated DEX/CRH test response remains speculative. Because the elevated response was found in responders as well as in non-responders, it seems to reflect an effect of lithium on the HPA system regulation putatively independent from the psychopathological state or its improvement.

Dexamethasone is metabolized by CYP3A4, the most important P450 enzyme. CYP3A4 inducing drugs like barbiturates and carbamazepine accelerate dexamethasone metabolization, which leads to higher ACTH and cortisol responses to CRH stimulation in the combined DEX/CRH test (von Bardeleben et al. 1988; Zobel et al. 2001). Contrary to carbamazepine, lithium is not known 
as a P450 enzyme inducer. As expected, we did not find any significant correlation between the lithium plasma levels and the ACTH or cortisol response in the DEX/ CRH test (peak ACTH: $\mathrm{r}=0.060, p=.78$; peak cortisol: $\mathrm{r}=-0.197, p=.36$; Pearson's correlation coefficient).

Early human studies conducted in the 1960s and 1970s already suggested a stimulating effect of lithium on the HPA system. Platman and coworkers repeatedly showed an increase of plasma cortisol levels in acutely affective ill patients a few days after initiation of lithium administration (Platman and Fieve 1968; Platman et al. 1971). In contrast, Sachar et al. (1970) did not find a change in mean plasma cortisol levels induced by lithium administration in a group of remitted patients with recurrent affective disorder.

One possible mechanism that may explain the effects of lithium on the HPA system is the well established interaction of lithium with the serotonergic system. Serotonergic axons project to neuroanatomically discrete areas throughout the brain but with extensive innervation of the limbic system and the paraventricular nucleus of the hypothalamus (Jacobs and Azmitia 1992). There is consistent evidence from animal studies that lithium enhances serotonergic responsiveness by actions on 5-HT turnover and release (de Montigny et al. 1983; Price et al. 1990). Lithium administration has been shown to enhance 5-HT release (Treiser et al. 1981) and 5-HT synthesis (Broderick and Lynch 1982) in the rat dorsal hippocampus. On the other hand, there is considerable evidence that serotonin plays an important role in the regulation of the HPA system (Spinedi and Gaillard 1991; Whitnall 1993). For example, the serotonin reuptake inhibitor fluoxetine was shown to cause the release of CRH in rats in vivo (Gibbs and Vale 1983) and the elevation of CRH RNA levels exclusively in neurosecretory nerve cells of the paraventricular nucleus in vitro (Torres et al. 1998). Thus, there is evidence that lithium may stimulate the ACTH and cortisol secretion through its stimulatory effects on the serotonergic system, which may induce an increase in CRH in the hypothalamus. Such mechanisms could account for the increase of the ACTH and cortisol response in the combined DEX/CRH test during lithium augmentation.

Moreover, there is evidence from in vitro studies and from animal studies that lithium has further direct effects on the HPA system. In rats and in cultured pituitary cells, ACTH and corticosterone were significantly increased after lithium administration, possibly by directly acting on the corticotrophs (Zatz and Reisine 1985; Reisine and Zatz 1987; Sugawara et al. 1988). However, in our study, ACTH serum levels before CRH stimulation were not significantly different between baseline and re-assessment.

The design of this study had some limitations that could confound interpretation of the data. First, the patients were treated with different antidepressants. Al- though there were no significant differences between responders and non-responders in the antidepressive medication, this might have influenced the results. However, antidepressant medication was kept constant throughout the study. Second, the follow-up DEX/ $\mathrm{CRH}$ test was performed at different time points in responders and non-responders. This study design was chosen to investigate the HPA system in responders as close to the time point of response as possible. Third, no control group of depressed patients treated with lithium monotherapy was included in the study.

In conclusion, this study showed an unexpected but marked effect of augmentation with the serotonergic agent lithium on HPA system regulation and gives reason to consider the possibility that the unclear mechanism of its action could be partly mediated by this endocrinological pathway. This study also questions the paradigm in major depression that the normalization of HPA system overstimulation in the combined DEX/ $\mathrm{CRH}$ test is a necessary prerequisite for clinical improvement. To further elucidate the effects of lithium on the HPA system, studies are needed to investigate the effects of lithium monotherapy on the HPA system in healthy controls, as well as in major depression, during the acute depressed state and during remission.

\section{ACKNOWLEDGMENTS}

Supported in part by the Permanent Commission for Research and Young Scientists of Freie Universität Berlin, FK 41/06/ 2000. Some findings of the present study are part of the doctoral thesis of U. E.

\section{REFERENCES}

Barden N, Reul JM, Holsboer F (1995): Do antidepressants stabilize mood through actions on the hypothalamic-pituitary-adrenocortical system? Trends Neurosci 18:6-11

Bauer M, Bschor T, Kunz D, Berghöfer A, Ströhle A, MüllerOerlinghausen B (2000): Double-blind, placebo-controlled trial of the use of lithium to augment antidepressant medication in continuation treatment of unipolar major depression. Am J Psychiatry 157:1429-1435

Bauer M, Döpfmer S (1999): Lithium augmentation in treatment-resistant depression - A meta-analysis of placebo-controlled studies. J Clin Psychopharmacol 19: $427-434$

Bauer M, Whybrow PC, Angst J, Versiani M, Möller HJ (2002): World Federation of Societies of Biological Psychiatry (WFSBP) guidelines for biological treatment of unipolar depressive disorders, Part 1: acute and continuation treatment of major depressive disorder. World J Biol Psychiatr 3:5-43

Baumann P, Nil R, Souche A, Montaldi S, Baettig D, Lambert $\mathrm{S}$, Uehlinger C, Kasas A, Amey M, Jonzier-Perey M (1996): A double-blind, placebo-controlled study of cit- 
alopram with and without lithium in the treatment of therapy-resistant depressive patients: A clinical, pharmacokinetic, and pharmacogenetic investigation. J Clin Psychopharmacol 16:307-314

Broderick P, Lynch V (1982): Behavioral and biochemical changes induced by lithium and L-tryptophan in muridical rats. Neuropharmacology 21:671-679

Bschor T, Berghöfer A, Ströhle A, Kunz D, Adli M, Müller-Oerlinghausen B, Bauer M (2002): How long should the lithium augmentation strategy be maintained? A 1-year follow up of a placebo-controlled study in unipolar refractory major depression. J Clin Psychopharmacol (in press)

Bschor T, Canata B, Müller-Oerlinghausen B, Bauer M (2001): Predictors of response to lithium augmentation in tricyclic antidepressant-resistant depression. J Affect Disord 64:261-265

de Montigny C, Cournoyer G, Morissette R, Langlois R, Caillé G (1983): Lithium carbonate addition in tricyclic antidepressant-resistant unipolar depression. Arch Gen Psychiatry 40:1327-1334

de Montigny C, Grunberg F, Mayer A, Deschenes JP (1981): Lithium induces rapid relief of depression in tricyclic antidepressant drug non-responders. Br J Psychiatry 138:252-256

de Montigny C (1994): Lithium addition in refractory depression. In Nolen WA, Zohar J, Roose SP, Amsterdam JD (eds), Refractory depression: Current Strategies and Future Directions. London, John Wiley \& Sons Ltd, pp 47-57

Dinan TG (1997): Neuroendocrinology of mood disorders. Curr Opin Psychiatry 10:84-87

Gibbs DM, Vale W (1983): Effect of the serotonin reuptake inhibitor fluoxetine on corticotropin-releasing factor and vasopressin secretion into hypophysial portal blood. Brain Res 280:176-179

Hamilton M (1960): A rating scale for depression. J Neurol Neurosurg Psychiatry 23:56-62

Heuser I, Yassouridis A, Holsboer F (1994): The combined dexamethasone/CRH test: a refined laboratory test for psychiatric disorders. J Psychiatr Res 28:341-356

Heuser I (1998): The hypothalamic-pituitary-adrenal system in depression. Pharmacopsychiat 31:10-13

Heuser IJE, Schweiger U, Gotthardt U, Schmider J, Lammers CH, Dettling M, Yassouridis A, Holsboer F (1996): Pituitary-adrenal-system regulation and psychopathology during amitriptyline treatment in elderly depressed patients and normal comparison subjects. Am J Psychiatry 153:93-99

Holsboer F, Lauer CJ, Schreiber W, Krieg JC (1995): Altered hypothalamic-pituitary-adrenocortical regulation in healthy subjects at high familial risk for affective disorders. Neuroendocrinology 62:340-347

Holsboer F (2000): The corticosteroid receptor hypothesis of depression. Neuropsychopharmacol 23:477-501

Jacobs BL, Azmitia EC (1992): Structure and function of the brain serotonin system. Physiol Rev 72:165-229

Joffe RT, Singer W, Levitt AJ, MacDonald C (1993): A placebo-controlled comparison of lithium and triiodothyronine augmentation of tricyclic antidepressants in unipolar refractory depression. Arch Gen Psychiatry 50: 387-393
Katona CLE, Abou-Saleh MT, Harrison DA, Nairac BA, Edwards DRL, Lock T, Burns RA, Robertson MM (1995): Placebo-controlled trial of lithium augmentation of fluoxetine and lofepramine. Br J Psychiatry 166:80-86

Platman SR, Fieve RR (1968): Lithium carbonate and plasma cortisol response in the affective disorders. Arch Gen Psychiatry 18:591-594

Platman SR, Hilton JG, Koss MC, Kelly WG (1971): Production of cortisol in patients with manic-depressive psychosis treated with lithium carbonate. Dis Nerv Syst 32:542-544

Price LH, Charney DS, Delgado PL, Heninger GR (1990): Lithium and serotonin function: implications for the serotonin hypothesis of depression. Psychopharmacology (Berl) 100:3-12

Reisine T, Zatz M (1987): Interactions among lithium, calcium, diacylglycerides, and phorbol esters in the regulation of adrenocorticotropin hormone release from AtT20 cells. J Neurochem 49:884-889

Sachar EJ, Hellman L, Kream J, Fukushima DK, Gallagher TF (1970): Effect of lithium-carbonate therapy on adrenocortical activity. Arch Gen Psychiatry 22:304-307

Spinedi E, Gaillard RC (1991): Stimulation of the hypothalamo-pituitary-adrenocortical axis by the central serotonergic pathway: involvement of endogenous corticotropin-releasing hormone but not vasopressin. J Endocrinol Invest 14:551-557

Steckler T, Holsboer F, Reul JM (1999): Glucocorticoids and depression. Baillieres Best Pract Res Clin Endocrinol Metab 13:597-614

Sugawara M, Hashimoto K, Hattori T, Takao T, Suemaru S, Ota Z (1988): Effects of lithium on the hypothalamopituitary-adrenal axis. Endocrinol Jpn 35:655-663

Thase ME, Rush AJ (1995): Treatment-resistant depression. In Bloom FE, Kupfer DJ (eds), Psychopharmacology: The Fourth Generation of Progress. New York, Raven Press, pp 1081-1097

Torres G, Horowitz JM, Laflamme N, Rivest S (1998): Fluoxetine induces the transcription of genes encoding c-fos, corticotropin-releasing factor and its type 1 receptor in rat brain. Neuroscience 87:463-477

Treiser SL, Cascio CS, O’Donohue TL, Keilar K (1981): Lithium increases serotonin release and decreases serotonin receptors in the hippocampus. Science 213:1529-1531

von Bardeleben U, Holsboer F (1991): Effect of age on the cortisol response to human corticotropin-releasing hormone in depressed patients pretreated with dexamethasone. Biol Psychiatry 29:1042-1050

von Bardeleben U, Wiedemann K, Stalla GK, Müller OA, Holsboer F (1988): Exaggerated corticotrophic cell response to human corticotropin-releasing hormone in two patients during long-term carbamazepine treatment. Biol Psychiatry 24:331-335

Watson S, Young AH (2001): The place of lithium salts in psychiatric practice 50 years on. Curr Opin Psychiatry 14:57-63

Whitnall MH (1993): Regulation of the hypothalamic corticotropin-releasing hormone neurosecretory system. Prog Neurobiol 40:573-629 
Wittchen HU, Wunderlich U, Gruschwitz S, Zaudig M (1997): SKID-I. Strukturiertes Klinisches Interview für DSM-IV. Achse I: Psychische Störungen. Göttingen, Hogrefe

Wood AJ, Goodwin GM (1987): A review of the biochemical and neuropharmacological actions of lithium. Psychol Med 17:579-600

Zatz M, Reisine TD (1985): Lithium induces corticotropin secretion and desensitization in cultured anterior pituitary cells. Proc Natl Acad Sci USA 82:1286-1290

Zobel AW, Nickel T, Sonntag A, Uhr M, Holsboer F, Ising M (2001): Cortisol response in the combined dexamethasone/CRH test as predictor of relapse in patients with remitted depression: A prospective study. J Psychiat Res 35:83-94 